\title{
Fatal cholangitis in a patient with biliary ascaridiasis
}

Colangite fatal em paciente com ascaridíase biliar

\author{
Rosilene Viana Andrade ${ }^{1,2}$, Marilaine Martins ${ }^{1,2,3}$ \\ e Marcus Vinícius Guimarães de Lacerda ${ }^{1,2,4}$
}

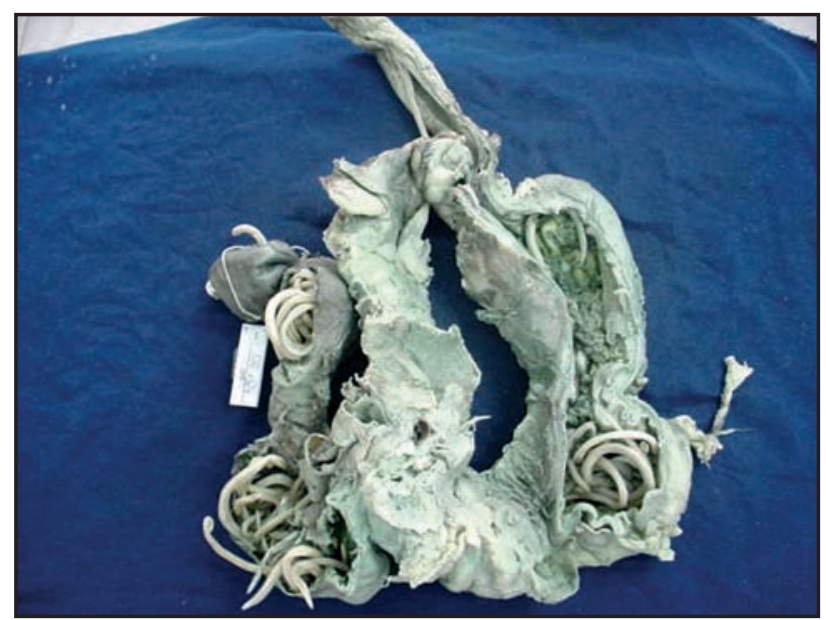

A

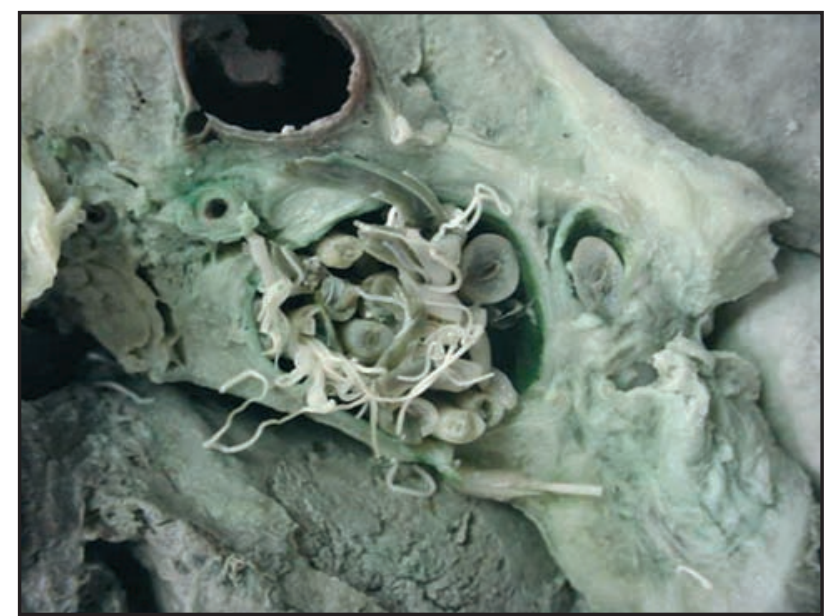

B

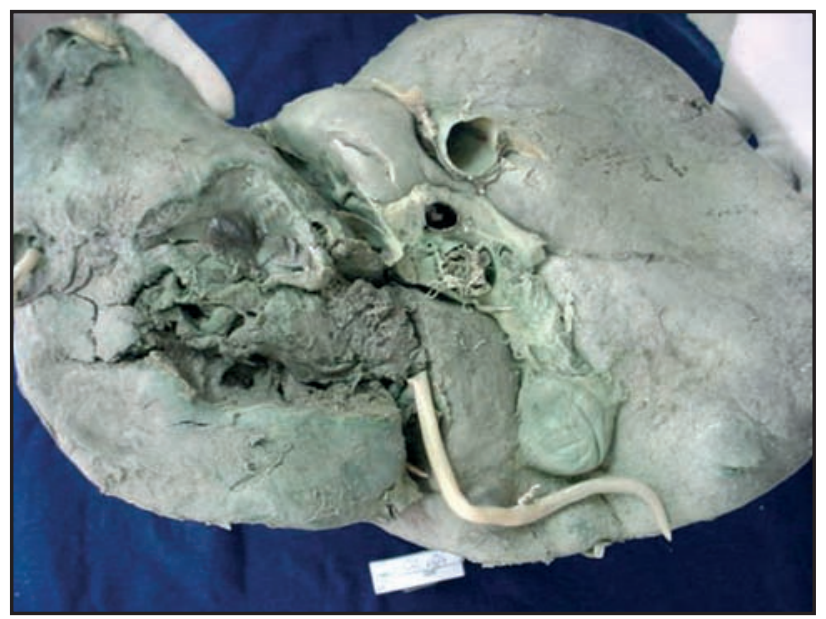

C

1. Fundação de Medicina Tropical do Amazonas, Manaus, AM. 2. Universidade do Estado do Amazonas, Manaus, AM. 3. Universidade Federal do Amazonas, Manaus, AM. 4. Centro Universitário Nilton Lins, Manaus, AM.

Adress to: Dr. Marcus Vinícius Guimarães de Lacerda. Fundação de Medicina Tropical do Amazonas. Av. Pedro Teixeira 25, Bairro Dom Pedro, 69040-000 Manaus, Amazonas, Brasil.

Telefax: 5592 3656-0620

e-mail: marcuslacerda@uol.com.br

Recebido para publicação em 5/12/06

Aceito em 27/4/07 
A 30-year-old woman, coming from Tefé (State of Amazonas), was hospitalized complaining of upper abdominal pain, fever, headache, nausea, vomiting and jaundice that had started 30 days before admission to hospital. At physical examination the patient was dehydrated, pale, jaundiced, tachypneic ( 40 breaths per minute), hypothermic $\left(33.5^{\circ} \mathrm{C}\right)$ and hypotensive. The liver was palpable $4 \mathrm{~cm}$ below the right costal margin. Laboratory tests revealed leukocytosis $\left(47,100 / \mathrm{mm}^{3}\right)$ with neutrophilia; hematocrit $10.4 \%$, serum creatinine $3.2 \mathrm{mg} / \mathrm{dl}$, urea $226 \mathrm{mg} / \mathrm{dl}$, AST 4,351 $\mathrm{U} / 1, \mathrm{ALT}=616 \mathrm{U} / \mathrm{l}$ and total bilirubin $65.2 \mathrm{mg} / \mathrm{dl}$ (direct bilirubin $47.8 \mathrm{mg} / \mathrm{dl}$ ). She received intravenous hydration, ceftriaxone, dopamine, transfusion of packed red cells and nasal oxygen; and she died two hours after being admitted to hospital. The autopsy revealed the presence of Ascaris lumbricoides (adults and larvae) in the stomach and small bowel (Figure A) and biliary tract (Figure B). Some intra-hepatic worms were also described (Figure C). Migration of such worms to the biliary tract usually leads to bacterial cholangitis and sepsis. It is important to rule out infestation due to Ascaris in patients with icteric febrile syndrome in the tropics.

Uma mulher de 30 anos, procedente de Tefé (Amazonas), foi hospitalizada com queixa de dor em abdômen superior, febre, cefaléia, náuseas, vômitos e icterícia com início 30 dias antes da admissão ao hospital. Ao exame físico a paciente estava desidratada, pálida, ictérica, taquipnéica (40 irpm), hipotérmica $\left(33,5^{\circ} \mathrm{C}\right)$ e hipotensa. 0 fígado estava palpável $4 \mathrm{~cm}$ abaixo da borda costal direita. Exames laboratoriais revelaram leucocitose $\left(47.100 / \mathrm{mm}^{3}\right)$ com neutrofilia; hematócrito de $10,4 \%$; creatinina sérica $=3,2 \mathrm{mg} / \mathrm{dL} ;$ uréia $=226 \mathrm{mg} / \mathrm{dL} ;$ AST $=4,351 \mathrm{U} / \mathrm{L} ;$ ALT $=$ 616U/L e bilirrubina total $=65,2 \mathrm{mg} / \mathrm{dL}$ (bilirrubina direta $=$ $47,8 \mathrm{mg} / \mathrm{dL}$ ). A paciente recebeu hidratação venosa, ceftriaxona, dopamina, transfusão de hemácias e oxigênio nasal, e morreu duas horas após a admissão. A autópsia revelou a presença de Ascaris lumbricoides (adultos e larvas) no estômago e no intestino delgado (Figura A) e trato biliar (Figura B). Alguns vermes intra-hepáticos também foram descritos (Figura C). A migração do verme para o trato biliar geralmente leva à colangite bacteriana e sepse. É importante afastar a infestação por Ascaris em pacientes com síndrome febril ictérica, em áreas tropicais.

\section{REFERENCES}

1. Araujo CF, Fernandez CL. Prevalence of intestinal parasitosis in the city of Eirunepe, Amazon. Revista da Sociedade Brasileira de Medicina Tropical 38:69, 2005.

2. Boia MN, Carvalho-Costa FA, Sodre FC, Eyer-Silva WA, Lamas CC, Lyra MR, Pinto VL Jr, Cantalice Filho JP, Oliveira AL, Carvalho LM, Gross JB, Sousa AL, Moraes TI, Bermudez-Aza EH, Martins EB, Coura JR. Mass treatment for intestinal helminthiasis control in an Amazonian endemic area in Brazil. Revista do Instituto de Medicina Tropical de São Paulo 48:189-195, 2006.

3. Okumura M, Nakashima Y, Curti P, de Paula W. Acute intestinal obstruction by Ascaris. Analysis of 455 cases. Revista do Instituto de Medicina Tropical de São Paulo 16:292-300, 1974. 